\title{
REDUÇÃO DO CONSUMO DE ÁCIDO NAS LINHAS DE GALVANIZAÇÃO*
}

Felipe $\mathrm{Krug}^{1}$

\section{Resumo}

A decapagem química, necessária para a remoção de óxidos e hidróxidos da superfície dos arames na galvanização contínua a fogo, emprega uma solução a base de ácido clorídrico que necessita constante monitoramento. O controle da temperatura e a concentração, são imprescindíveis para obtenção de custos competitivos, qualidade de produtos e manutenção da segurança operacional. Este trabalho realizou uma crítica, nas práticas e controles já implantados, identificando desperdícios e oportunidades e fazendo um re-alinhamento do processo alterandose parâmetros e rotinas de forma a obter o menor custo, mantidas qualidade $e$ segurança operacional.

Palavras-chave: Decapagem química; Arames galvanizados; Ácido clorídrico.

\section{REDUCTION OF ACID CONSUMPTION IN GALVANIZING LINES}

\section{Abstract}

The pickling is a necessary process for wire oxides and hydroxides surface remuvel in continuous galvanizing. It uses a solution of hydrochloric acid that requires continuous monitoring. The temperature and concentration controls, are essential to reach competitive costs, hight quality produtcs and keeping operational safety. This work has made a review, of current practices and controls, identifying wastes and opportunities and made changes in parameters and routines in order to obtain the lowest cost, maintained product quality and operational safety.

Keywords: Picking; Galvanized wire; Hydrochloric acid.

1 Engenheiro Mecânico, Mestre em Siderurgia, Assessor Técnico/Facilitador de Melhorias, Trefila 2, Gerdau Aços Brasil, Gerdau Riograndense, Sapucaia do Sul, RS, Brasil. 


\section{INTRODUÇÃO}

No processo de galvanização à fogo, para eliminar qualquer barreira entre o zinco e seu substrato que possam resultar em falhas, defeitos ou falta de aderência é necessária a imersão dos arames em um tanque contendo uma solução de ácido clorídrico para a remoção de óxidos e hidróxidos e mesmo de óleos e graxas queimados provenientes do processo de trefilação ou armazenagem da matéria prima. Este banho possui alguns parâmetros que necessitam ser controlados e foram determinados em conjunto com o fabricante para a linha de produtos a ser processados de acordo com o VD (relação entre velocidade de processamento e diâmetro de material) da linha:

a) Concentração de Ácido Clorídrico;

b) Temperatura de Trabalho;

c) Nível do Banho (entre mínimo e máximo);

d) Contaminação por Fe (Cloreto de Ferro II);

Pelo entendimento, na prática o afastamento dos resultados desses parâmetros, implica em desvios na qualidade do produto, danos em equipamentos e riscos de segurança operacional.

Para a manutenção da concentração do ácido, o equipamento possui um tanque de transferência, que era adicionado por completo uma vez ao dia de acordo com o resultado análise da concentração, no turno em que a mesma se aproximava do limite inferior da faixa de trabalho. Essa faixa de trabalho é abrangente e atendia com qualidade todas as bitolas processadas no equipamento, sem distinção de itens. Na Fig. 1 se apresentam os limites e resultados de medição obtidos na operação do equipamento em um dos meses de observação do trabalho.

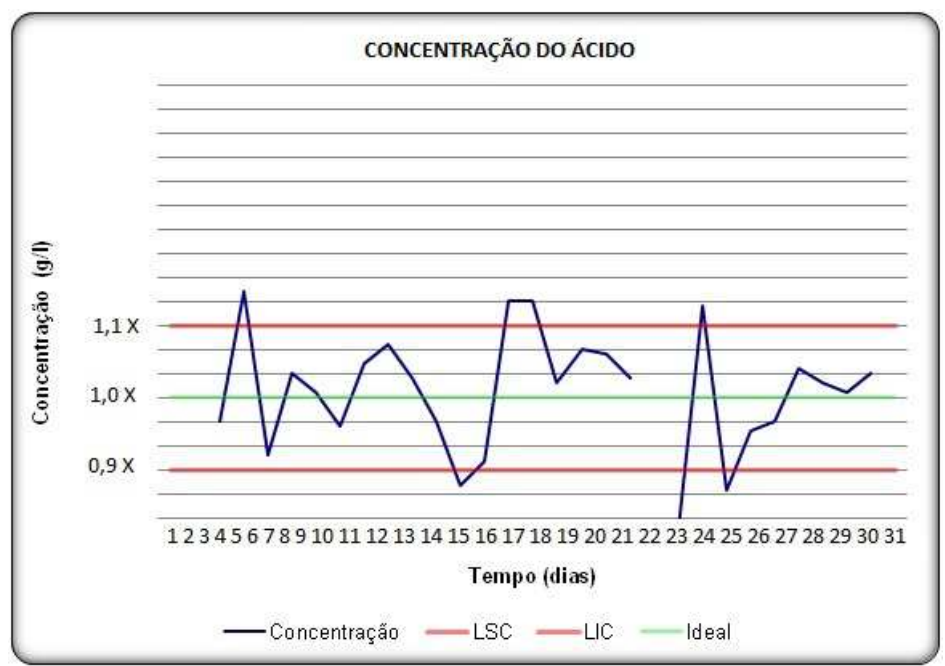

Figura 1. Concentração de Ácido Decapagem LZ2.

Em alguns pontos o ácido apresentava resultados acima e abaixo do estabelecido sendo que àqueles acima impactam em um gasto desnecessário de ácido. As leituras do dia 22 e 23 são relativas a uma parada para manutenção preventiva. Uma variabilidade excessiva também fica evidente com variações de até $0,4 \mathrm{X}$ entre medições sendo que a faixa estabelecida é de $0,2 \mathrm{X}$.

Periodicamente, os tanques são esvaziados e tem seu conteúdo direcionado para um tanque pulmão para a realização de limpeza. Esse efluente é enviado para tratamento físico-químico e estabilização antes do descarte. O tanque é limpo por um sistema de hidro-jateamento e sucção, que remove o lodo contaminado. 
Após a manutenção de pedras raspadoras e bombas, um novo banho é preparado buscando-se a concentração nominal para reiniciar sua operação.

A ocorrência de desvios na concentração seja por superdosagem, falhas em equipamentos, vazamentos ou quaisquer outro que atinja os gatilhos estabelecidos para o processo são tratados via TF's (metodologia de tratamento de falhas) e sanados.

\section{MATERIAIS E MÉTODOS}

Dentro da análise, além das cartas CEP, foram utilizados o Brainstorm, Diagramas de Causa e Efeito, Matriz GUT e Teste de Hipóteses para analisar cada uma das práticas, identificando potencias de ganhos no processo.

\subsection{Concentração do Ácido}

Aumentando a concentração do ácido o tempo de decapagem cai. Tendo em vista que trabalha-se com um VD definido para a linha de galvanização, que integra diversos processos, a velocidade dos arames foi um parâmetro que se manteve constante pois sua alteração implicaria em outros impactos não controlados por este trabalho.

Sobram então basicamente duas formas de reduzir consumo de ácido, uma delas é reduzir o desperdício e a outra é torná-lo mais eficaz.

No caso da concentração se observou que a faixa de trabalho fora definida tendo em vista o resultado dos itens mais críticos, que possuíam uma relação de tempo de imersão/ área mais baixos (maiores diâmetros e altas velocidades), assim mesmo que aqueles itens não estivessem nas ordens de produção do dia, a concentração do ácido era mantida alta para atendimento de parâmetros, representando um desperdício desnecessário para o bom andamento do processo.

A periodicidade e o volume das adições também foram analisados, pois geram uma variabilidade muito grande sendo que o comportamento horário da concentração em produção normal fora observado e apresentou o comportamento da Fig. 2.

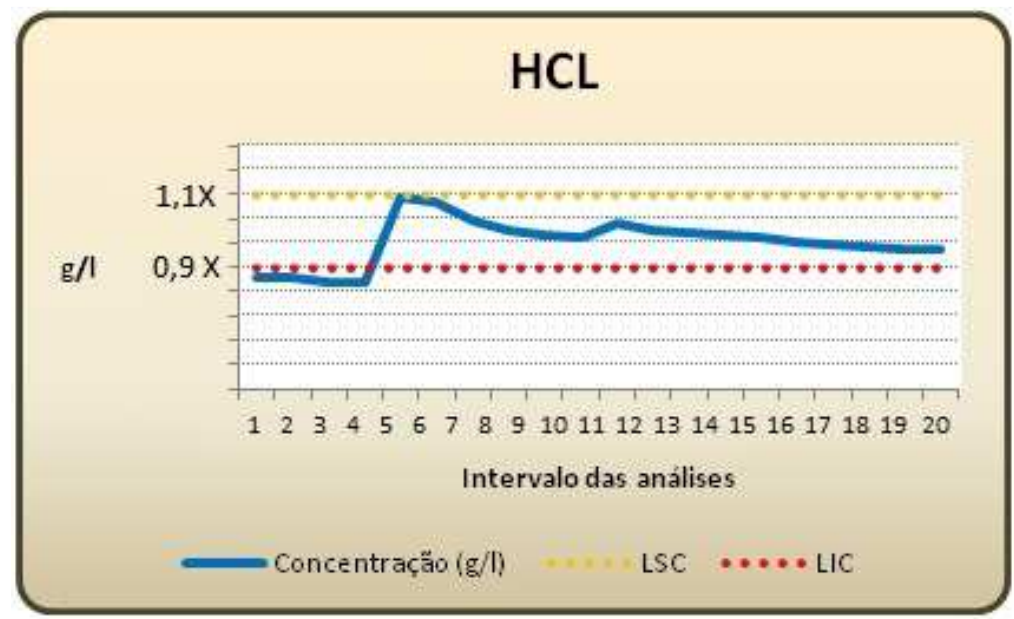

Figura 2. Concentração Horária de Ácido Decapagem LZ2.

A análise das curvas demonstrou que quando em concentrações maiores $(1,1 \mathrm{X})$, perde-se cerca de $0,02 \mathrm{X} /$ hora e quando se parte de concentrações menores $(1,0 \mathrm{X})$ essa taxa passa a ser inferior à $0,01 \mathrm{X} /$ hora. 


\subsection{Temperatura}

Aumentando-se a temperatura, o tempo de decapagem cai. Aqui a elevação da temperatura poderia representar um ganho de eficácia na decapagem, mas o parâmetro foi analisado e deixado em segundo plano pela estabilidade apresentada e pelo processo já trabalhar em um limite considerado adequado para a melhor efetividade do ácido e existirem fatores de segurança que implicariam em riscos de segurança excessivos sobre os ganhos possíveis de se obter. Esse parâmetro é controlado por um sistema que trabalha com alarmes e que possui uma boa regularidade na prática do dia-a-dia.

\subsection{Nível do Banho}

O nível do banho tem impacto direto no processo de duas formas:

1) Estando abaixo do mínimo danifica as bombas além do ácido não subir em quantidades suficientes para a distribuição sobre o arame. O nível mínimo é representado em uma vigia junto à decapagem por uma linha vermelha posicionada em uma altura imediatamente acima da entrada de sucção das bombas.

2) Estando acima do nível máximo, representa que parte da adição de ácido, foi desperdiçada pois o nível máximo é representado junto a vigia junto da decapagem por uma linha vermelha posicionada imediatamente abaixo de um tubo de descarte que fica normalmente aberto e serve para evitar transbordamento por janelas de inspeção e suporte de bombas.

\subsection{Contaminação por Fe}

Nos banhos de decapagem com ácido clorídrico, em um primeiro momento a presença do ferro e o aumento de seu teor funcionam como um acelerador da reação até uma determinada concentração. Quanto maior a temperatura do banho, maior a concentração de ferro é possível antes do Fe passar de acelerador para retardador. Os valores de referência abaixo correlacionam o tempo de decapagem de amostras, variando-se a concentração de ácido, temperatura e concentração de Cloreto de Fe II

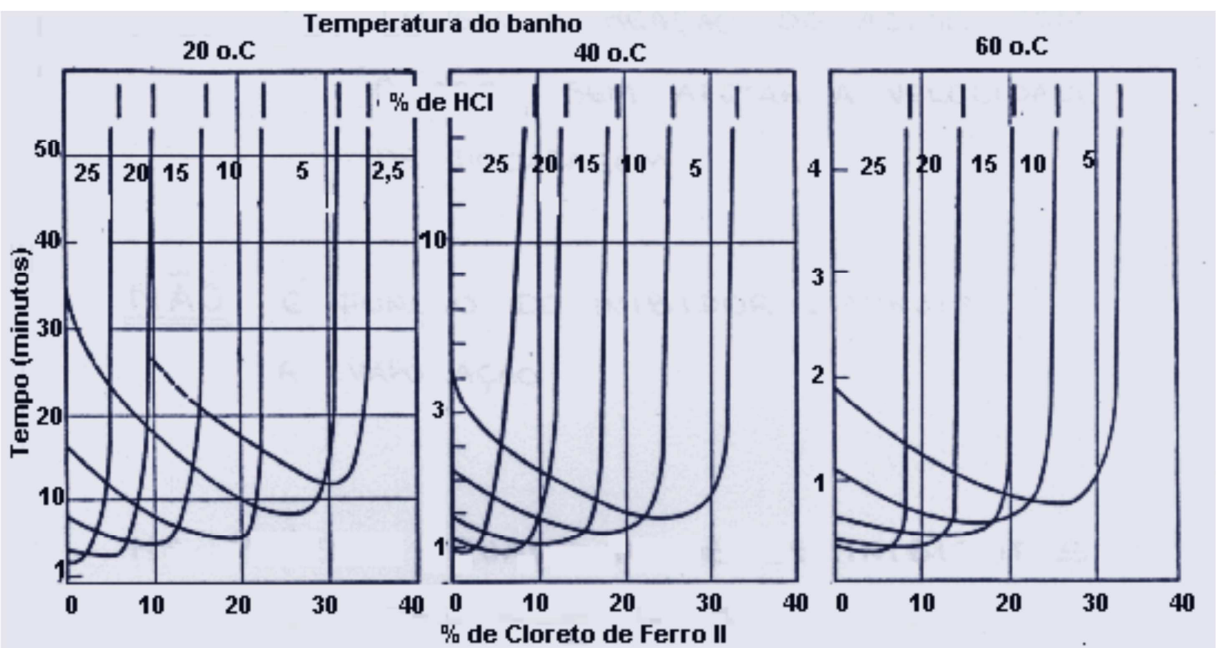

Figura 3. Temperatura de Trabalho vs Concentração de Ácido vs \% Fe vs Tempo Decapagem. 
Os resultados analisados da concentração de ferro do banho da decapagem dia a dia demonstram que para a temperatura de operação o limite não é atingido em nenhum momento. Isso se explica pelo funcionamento normal da decapagem onde arame arrasta parte do banho para águas de lavagem na saída e parte da água de resfriamento na entrada, para o banho de decapagem, mantendo a concentração de Fe em níveis aceitáveis.

\begin{tabular}{|c|c|c|c|c|}
\hline Amostra: & Ácido cloríc & asto & & \\
\hline Parametro & Unidade & $\mathrm{x}$ & $\mathrm{x}$ & $\mathrm{x}$ \\
\hline Teor de ácido cloridrico & \% p.p. & & & \\
\hline Ferro & $\mathrm{mg} / \mathrm{kg}$ & $1,53 \%$ & $1,35 \%$ & $7,91 \%$ \\
\hline Zinco & $\mathrm{mg} / \mathrm{kg}$ & $\mathrm{x}$ & $x$ & $\mathrm{x}$ \\
\hline Chumbo & $\mathrm{mg} / \mathrm{kg}$ & $x$ & $x$ & $x$ \\
\hline Aluminio & $\mathrm{mg} / \mathrm{kg}$ & $\mathrm{x}$ & $x$ & $\mathrm{x}$ \\
\hline pH 10\% & $\mathrm{mg} / \mathrm{kg}$ & $\mathrm{x}$ & $\mathrm{x}$ & $\mathrm{x}$ \\
\hline Num. Laudo & & 229343 & 232761 & 242791 \\
\hline
\end{tabular}

Figura 4. Concentração \% de Fe no Banho Ácido da Decapagem LZ2.

Esse fato levou a discussão de um ponto importante: o descarte do banho para limpeza dos tanques não só não se fazia necessário, pelo não atingimento da concentração limite, como também quando há a elaboração de um novo banho o acelerador não está presente nos primeiros momentos reduzindo a eficácia da decapagem. E ainda quanto maior a concentração do banho menor este limite de inversão. Logo trabalhar com concentrações menores permite um nível de Ferro maior antes da inversão.

\section{RESULTADOS E DISCUSSÃO}

\subsection{Resultado das Ações Revisadas nos Padrões}

As ações de redução de consumo basicamente atacaram 2 frentes.

\subsubsection{Reavaliar as concentrações de trabalho}

A concentração de trabalho antes fixada em $0,9 \mathrm{X}$ à $1,1 \mathrm{X}$ foi reduzida a partir da instalação de prensas de mantas para remoção do excesso de sabões de alguns materiais que necessitavam de altas concentrações para sua remoção. Com a diferenciação de acordo com os materiais a serem produzidos duas novas faixas, $0,55 X$ à $0,78 X$ e $0,73 X$ à $0,78 X$, foram inclusas nos padrões de fabricação (Fig 5), separando os materiais com menor relação de tempo de imersão por área, sendo que a nova regra institui que o valor dominante seja sempre o maior. 


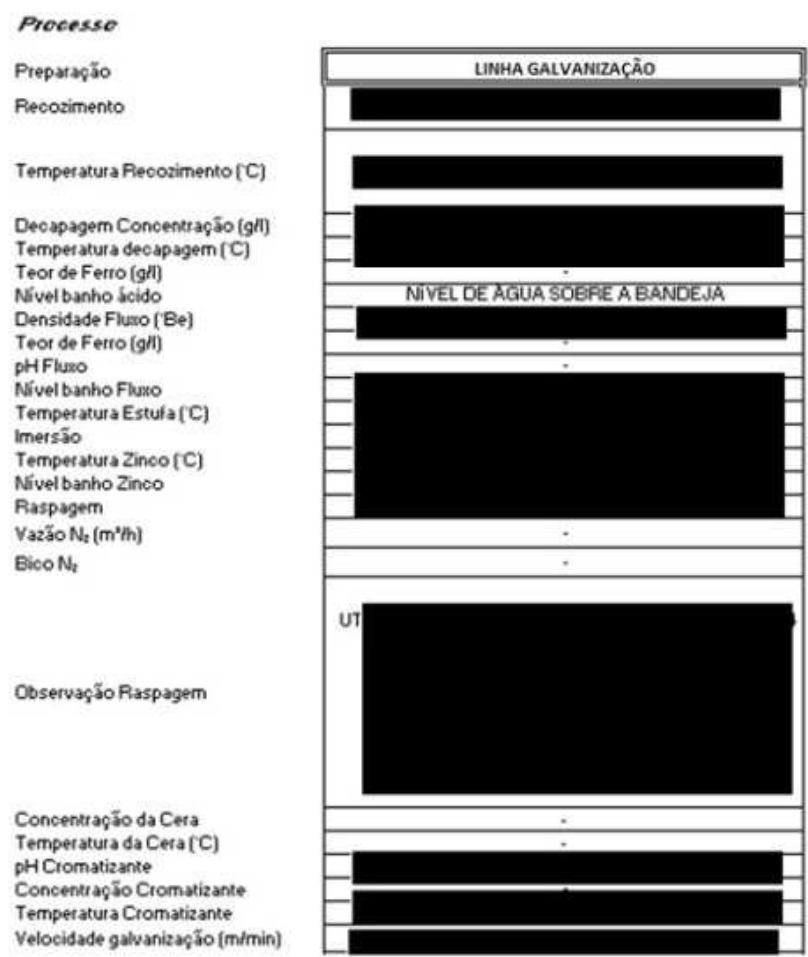

Figura 5. Exemplo de um Padrão de Fabricação de Item Galvanizado.

A figura 6 mostra a tabela de correção implementada, garantindo que apenas seja adicionada a quantidade ideal. Adicionalmente a esta tabela se implementou a rotina de não mais realizar uma adição diária mas três, sendo que estas adições não deveriam buscar o valor máximo da faixa de trabalho mas sim apenas o suficiente para que o valor da concentração permaneça dentro da faixa especificada até a correção do turno seguinte (razão da redução de concentração em função do tempo).

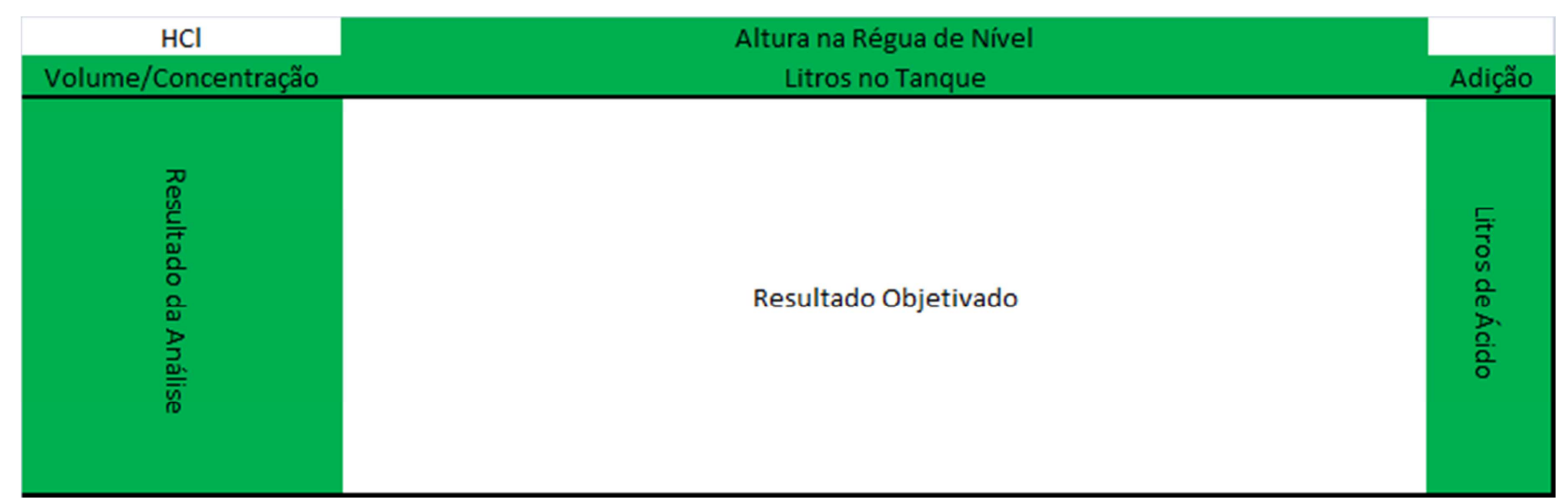

Figura 6. Tabela de Correção.

Para que isso fosse possível se instalou um medidor de vazão e totalizador nas linhas de abastecimento do ácido puro permitindo maior precisão na operação de adição (Fig. 7). 


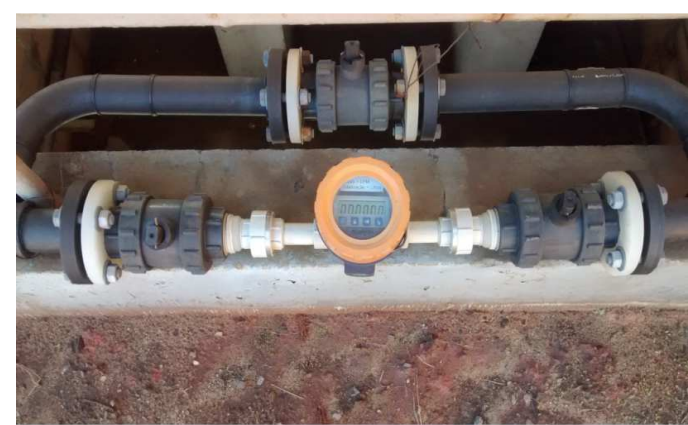

Figura 7. Totalizador e Medidor de Vazão.

Outra ação, de cunho gerencial mas tomada pelas análises dos resultados da concentração foi a de otimizar o planejamento e controle da produção, aglomerando itens de concentração mais alta, produções maiores e períodos menores (mais fios em menos dias).

\subsubsection{Manter o nível de Ferro na decapagem}

Para manter o nível de Fe na decapagem adotou-se uma prática nas preventivas: alterar o descarte e limpeza dos banhos. Antes descartados por completo, os banhos após algum tempo parados, passaram a ser transferidos para unitainers até o nível inferior das bombas (onde historicamente se apresenta o lodo retirado por hidro-jateamento e sucção). Assim não só se garante a presença de ferro na partida, funcionando como acelerador da reação como também se reduziu a quantidade necessária de adição de ácido no retorno das limpezas pois a parte transferida de volta para os tanques ( $75 \%$ do volume) já apresenta a concentração dentro do parâmetro.

O resultado do conjunto de ações tomadas podem ser vistas nos resultados das medições de concentração representados na carta CEP (Fig 8).

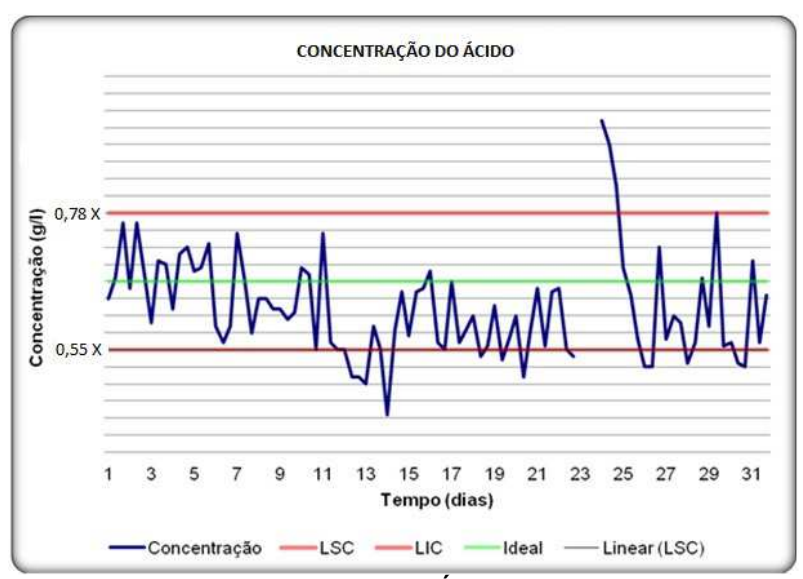

Figura 8. Concentração de Ácido Decapagem LZ2.

$\mathrm{Na}$ figura 9 pode-se verificar o resultado do trabalho onde se reduziu o consumo médio de ácido por tonelada de arame produzida em $33 \%$ com a implementação das ações citadas a partir de setembro anteriormente além de ter uma estabilização do resultado. 


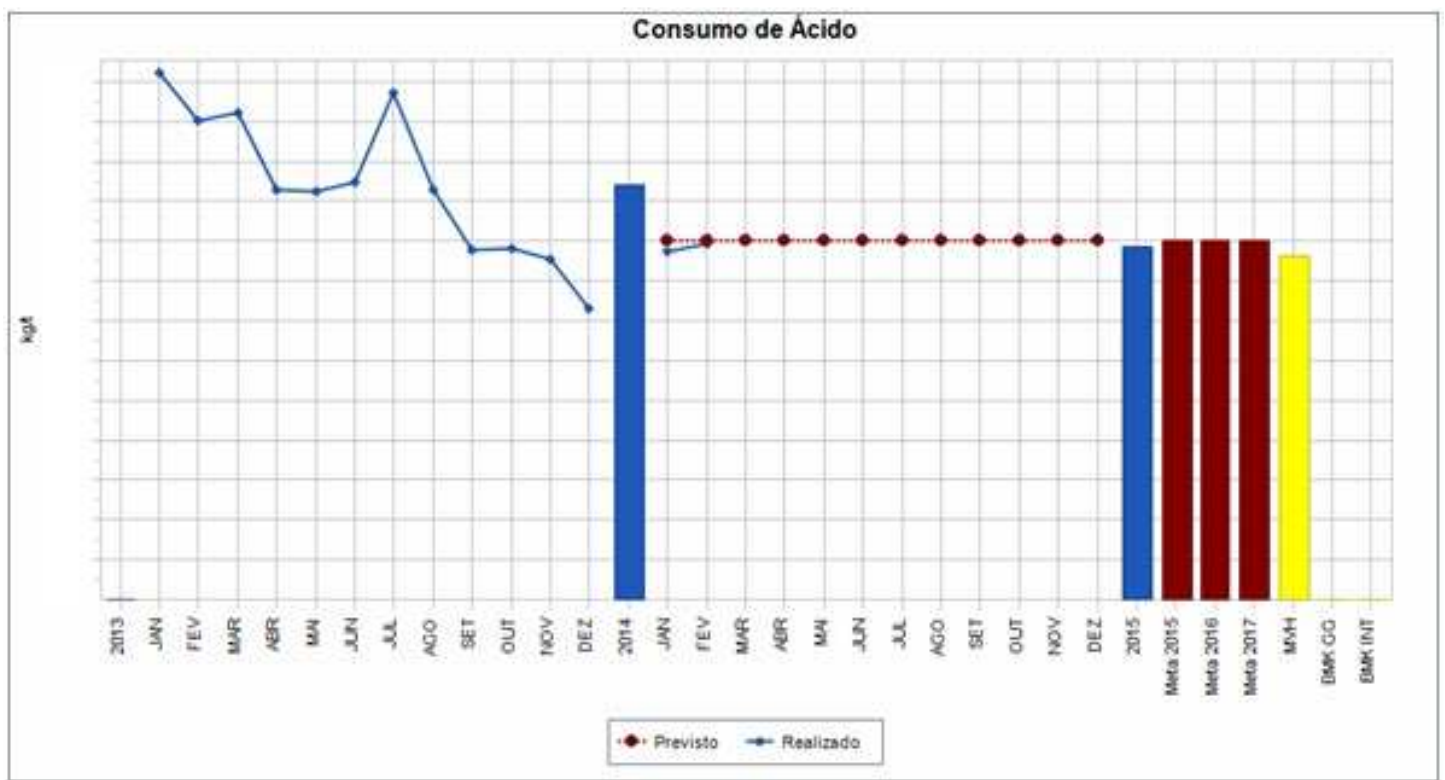

Figura 9. Consumo de Ácido LZ2.

Outros ganhos foram verificados como consequência do trabalho: redução de insumos no tratamento de efluentes, e ganhos redução do Kgiro pela redução de estoque de ácido e menor ponto de reposição.

\section{CONCLUSÃO}

Após a implementação das ações, reforça o sentimento de que nunca podemos deixar de reavaliar nossos processos simplesmente por estarem estáveis, e que a competitividade imposta pela concorrência deve ser um estimulador na busca de desafios. Devemos questionar práticas já consolidadas e consideradas seguras, mas que não garantam o melhor resultado financeiro.

Muito do que foi realizado, foi feito de forma empírica, a partir de testes práticos, buscando os limites do processo, no processo, mas sempre observando o embasamento teórico.

Concluímos que os resultados obtidos foram um grande avanço frente ao consumo histórico mas também trouxe a percepção que ainda é possível reduzir mais os níveis de consumo de ácido com pequenos investimentos, e que o limite do processo ainda não foi atingido, podendo-se ainda extrapolar os limites do consumo de ácido da galvanização a novos patamares.

\section{Agradecimentos}

Gostaria de agradecer aos colegas da Célula de Galvanização da Gerdau Riograndense, integrantes do grupo de GSP responsáveis pelo resultado prático deste trabalho, pelo apoio e confiança em mim depositados como padrinho do projeto. A todos meus colegas de área que direta ou indiretamente contribuiriam para o êxito do projeto. Com certeza todos os questionamentos e contribuições estimularam a busca de soluções diferentes, e trouxeram novos resultados 


\section{BIBLIOGRAFIA}

1 GERDAU. Trefilação TRE-505: Preparação para Galvanização. Porto Alegre, 2008

2 GERDAU. Trefilação TRE-506: Galvanização. Porto Alegre, 2002

3 CAMPBELL, J .S. Principles of Manufacturing Materials and Processes International Studies. New York: McGraw-Hill, 1961.

4 CETLIN, P.R. Tecnologia de Trefilação de Arames de Aço, Apostila de Supervisores, UFMG, 1994

5 YOUSSEF, H. A.; EL-HOFY, H. A. e AHMED, M. H. Manufacturing Technology: Materials, Process and Equipment. Boca Raton: CRC Press, 2011. 913p. 